\title{
Does Work Environment Affect Faculty Health Scores?
}

\author{
Rhonda C. Magel \\ Department of Statistics, North Dakota State University, Fargo, USA \\ Email: rhonda.magel@ndsu.edu \\ Received August $7^{\text {th }}, 2013$; revised September 11 $1^{\text {th }}, 2013$; accepted September $28^{\text {th }}, 2013$
}

Copyright (C) 2013 Rhonda C. Magel. This is an open access article distributed under the Creative Commons Attribution License, which permits unrestricted use, distribution, and reproduction in any medium, provided the original work is properly cited.

\begin{abstract}
This study investigates the relationship between self-reported health scores with work environment and various components of a women faculty score at a Research 1 University in the Midwest USA. The study examines the differences between male and female faculty responses in the various components making up the women faculty score and also gender differences in self-reported health scores and work environment scores. Differences between STEM and Non-STEM faculty are examined. A significant positive relationship is found between self-reported health scores and work environment controlling for gender. The study finds that the overall university work environment has a stronger relationship to faculty health than adequate gender ratio, women climate, and women leadership, even for women faculty. No significant differences in responses are found between STEM and Non-STEM faculty for women climate, women leadership, health scores, and work environment scores. Significant differences are found only in adequate gender ratio.
\end{abstract}

Keywords: Higher Education; Gender Differences; STEM Fields; Job Climate

\section{Purpose}

The purpose of this research is to investigate any relationship of health with work climate and other environmental factors for faculty in higher education. This study is interested in any gender effects and whether or not any relationships among these factors differ between Science, Technology, Engineering, and Mathematics (STEM) faculty and Non-STEM faculty.

\section{Previous Studies}

\section{Previous Gender Studies in Higher Education}

During the past several years, studies have been conducted to evaluate gender differences. Some of this research has focused on salary inequities including studies by Thacker (1995); Balzer and Bourdreau (1996); Bourdreau, Sullivan, Balzer, Ryan, Yonker, Thorsteinson, and Hutchinson (1997); Bellas (1993); Sosin, Rives, and West (1998); Burke, Duncan, Krall, and Spencer (2005); Toumanoff (2005); Porter, Toutkoushian, and Moore (2008); Barbezat and Hughes (2005); Travis, Gross, and Johnson (2009). Others have presented methods to help correct for gender differences in salary including work by Oaxaca and Ransom (2002), Weistroffer, Spinelli, Canavos, and Fuhs (2010), and Haney and Forkenbrock (2006).

Student evaluation of teaching and gender impact has been studied by Laube, Massoni, Sprague, and Ferber (2007); Brady and Eisler (1999); Worthington (2002); Burns-Glover and Veith (1995); Sprinkle (2008). One study found that male teachers were more often classified by their students as professors while female teachers were more often classified as instructors (Miller $\&$ Chamberlin, 2000).

The work climate and environment of women faculty mem- bers has also been studied. Bronstein and Farnsworth (1998) reported from the results of a campus climate survey that women were more likely to feel left out, discriminated against by students, and treated unfairly in promotions and tenure decisions. Cress and Hart (2009) reported their findings at two different universities saying that men and women faculty members within the same university and department often experience different environments.

Some studies have focused on women in science and engineering fields (STEM disciplines). In particular, a survey was done on women faculty in the College of Science at Massachusetts Institute of Technology (MIT) in 1999 and followed up in 2003. In 2004, a set of matched men faculty were also interviewed at MIT. The researchers in the MIT study found that women were more likely to be given larger service loads, more likely to feel left out of interactions with colleagues, and more likely to feel stressed from a work/family life balance due to university policies. Women were also more likely to feel unfairly treated in promotional and tenure decisions (Hult, 2005). A study by Blackwell, Synder, Mavriplis (2009) found that women in STEM fields reported a more negative environment.

There has been research which relates the work climate and environmental conditions of women faculty to job and career satisfaction. August and Waltman (2004) found that overall career satisfaction for faculty women was related to their environmental conditions using Hagedorn's (2000) model. August and Waltman found that having a mentor, and salaries comparable to their male counterparts, resulted in a more positive work environment for women faculty. They also found that having collegial peer relations was significant for non-tenured women and being involved with departmental relations was significant for tenured women for a more positive environment. 
Hult (2005) found that women faculty were less likely to be satisfied with their job or career because of the more negative environmental conditions. Settles, Cortina, Malley, and Stewart (2006, 2007) found that a negative environment led to lower job satisfaction among women faculty.

Other research examining the relationship between campus environment and job or career satisfaction have reported similar findings (Glen, 2007), Greene, Stockard, Lewis, and Richmond (2010), Blackwell, Synder, Mavriplis (2009), and Cress and Hart (2009). Glen (2007) reports on a survey of 962 full-time faculty members at one university that finds women felt they were more likely to be ignored and they were more likely to be stressed. Viefers, Christie, and Ferdos (2006) discuss their findings as to why they feel there are very few women on physic faculties in Sweden.

$\mathrm{Xu}$ (2008) found that the faculty turnover rate for women in higher education institutions in the STEM disciplines was higher than for men. Xu's research links the higher turnover rate with women receiving less support, having fewer opportunities for advancement, and not as much of an opportunity to have a voice.

\section{Previous Studies Linking Job Climate with Health}

Studies have been conducted examining the relationship between job climate/environment with physical and psychological health of various types of workers. Some of these studies have involved gender. Messing, Lippel, Demers, \& Mergler (2000) studied occupational illnesses with regard to gender in blue collar workers in Canada. Their research found that women reported more sicknesses and occupational illnesses than men. Holmgren, Hensing, and Dellve (2010) studied the relationship between organizational climate and number of days absent because of sickness in the general population in Sweden. Findings were similar to the studies of Messing et al. (2000). Abramson (2007) studied mid-life women (ages 40 - 54) in various jobs in Canada and found that women working in negative environmental conditions were more likely to suffer from physical and/or mental ailments.

Miner-Rubino, Settles, Stewart (2009) considered a sample of 87 college educated white women and looked at their perceptions of workplace climate, job satisfaction, and general health. If a woman had a positive perception of her workplace climate, and there were a larger percentage of women at the level above, the woman's general health seemed to be higher than when compared to the general health of women who had a smaller percentage of women at the level above and a positive workplace climate. When the woman responding had a negative perception of her workplace climate, and there were a larger percentage of women at the level above, the woman's general health was generally worse than when there was a smaller percentage of women at the level above. It appears that workplace climate is an important factor in the general health of women and the number of women at the level above the subject has an interaction effect with climate. Miner-Rubino et al. (2009) found these findings with regard to the general health of a woman were particularly strong for women sensitive to sexism.

Dollard and Bakker (2010) examined the association between workplace climate and psychological health of education workers in Australia. Their research suggested an association between workplace climate and health.

\section{Previous Health/Climate Studies in Universities}

There has been some recent research studying the relationship between health and environment in higher education. Tytherleigh, Jacobs, Webb, Ricketts, \& Cooper $(2005,2007)$ studied occupational stress and work environment in English Higher Education Institutions. They found that women reported a significantly higher level of stress at the older universities which were more male dominated. Jacobs, Tytherleigh, Webb, and Cooper (2007) found that a poorer work environment for employees at English Higher Education Institutions was also associated with lower levels of job performance and more work days missed because of the increase in physical and mental health problems.

Catano, Francis, Haines, Kirpalani, Shannon, Stringer, \& Lozanzki (2010) studied occupational stress and work environment in Canadian universities. Their study found that women reported significantly higher stress levels in the following areas: work-life conflict; unfairness by the administration; unfairness in rewards; and work load.

Winefield, Gillespic, Stough, Dua, Hapuarachchi, \& Boyd (2003) studied stress of workers in Australian universities. The study found that faculty had higher reported stress levels than non-faculty.

\section{Previous Efforts to Improve Climate}

Efforts have been made to improve the campus environment for women. Henry and Nixon (1994) discuss some of these efforts. Piercy, Giddings, Allen, Meszaros, and Joest (2005) introduced pilot programs to help improve the environment of all faculty members, particularly those of color. In 2005, the President of Harvard announced that 50 million dollars would be spent over the next 10 years in an effort to improve campus climate for everyone (Fields, 2005). The University of Wisconsin-Madison has been holding departmental workshops on improving climate and has made documents available online to help improve the department climate including "Recommended Actions for Enhancing Department Climate" (2011) and "Enhancing Department Climate: A Guide for Department Chairs" (2011). Abadie, Christy, Jones, Wang, and Lima (2009) conducted a longitudinal survey of women faculty in biological and agricultural engineering in the hopes of finding ways to help improve the climate of women in these areas. Unfortunately, Valian (2004) writes that progress is slow in climate change for women faculty.

\section{Summary of Previous Studies}

Summarizing the aforementioned studies, women faculty in higher education often face a more negative climate/environment than men faculty, particularly in the STEM disciplines. This more negative climate has led to a lower percentage of women faculty in higher education satisfied with their jobs and/or careers. Studies in the general population have found that a more negative climate/environment for women more often results in physical and mental health symptoms (Miner-Rubino et al., 2009; Abramson, 2007; Messing et al., 2000). Some studies at higher education institutions have suggested this may also be true for women in higher education particularly at male dominated universities (Tytherleigh et al., 2007; Catano et al., 2009). There also have been studies that have suggested that there is more stress in academic jobs than 
other jobs (Tylerleigh, Webb, Cooper, \& Rickets, 2005). Women in jobs that reported more stress and a poorer environment have more sickness. If academic jobs cause even more stress than the norm and female faculty have higher levels of stress than male faculty, female faculty could have more physical ailments. This could be further magnified for mid-life female faculty if the findings for the general population hold true for female faculty in higher education (Abramson, 2007).

\section{Purpose of Research}

The main questions that arose after examining the past literature are the following: "Is there a relationship between a faculty member's general health and the work climate or other environmental factors after controlling for gender?" and "Is there a difference in the work climate and other environmental factors between STEM and Non-STEM faculty? If there is a difference, does this difference affect the overall health of a faculty member?"

\section{Description of Variables}

Research conducted at a Research 1 university in the Midwest was designed to help answer the previous questions and to study the relationship of self-reported general health of both male and female faculty members along with various factors within the university. A work life survey was composed consisting mainly of questions taken from the WESLLI survey with a few questions adapted to fit the university being surveyed (Faculty Work life Survey, 2006). Institutional Review Board Approval was obtained for the study. The survey was administered electronically through a faculty listserv. The survey went out to all tenured or tenure-track faculty members in mid-December 2008. Faculty were given through early February 2009 to respond. There were 224 faculty members who responded to at least some of the questions on the survey out of a total of 488 faculty members. This was a $45.9 \%$ response rate. Responses were anonymous and collected by a third party not involved with this research. Data is given on the North Dakota State University_Forward webpage (NDSU 2010).

Several questions on the survey were combined to form three scores for all responding faculty members. These three scores were the following: work environment score; composite health score; and women faculty score. The work environment score for a faculty member was a combined score based of the faculty member's responses, each on a four point scale, to statements on the following 19 items: respected by colleagues; respected by students; respected by staff; respected by chair; excluded form informal network; encounter unwritten rules; colleagues solicit my opinion; research is mainstream; colleagues value my research; a lot of work not formally recognized; "fit in"; feel isolated in department; feel isolated at the university; full and equal participant; voice in resource allocation; meetings allow shared views; committee assignments are fair; chair involves me in decision-making; and overall satisfaction with job at the university. The response that a faculty member gave to his/her overall job satisfaction counted double in their work environmental score. Responses were recoded for each of the 19 items so that a higher response indicated the faculty member was more positive on that item. A faculty member could receive a work environment score between 20 and 80 . A score of 50 indicated a "neutral" work environment. A score below 50 would indicate a "negative" work environment. A score above 50 would indicate a "positive" work environment.

The composite health score for a faculty member was based on the faculty member's responses to their overall health (this counted double); and whether or not they were happy, fatigued, stressed, nervous, depressed, short-tempered, well-rested, or physically fit. All responses to individual components were based on a four point scale. The points were assigned to the individual items so that a higher score was better. The minimum health score that a faculty member could receive was 10 and the maximum score was 40 . A score of 30 indicated "good" health while a score of 20 indicated "fair" health, with the middle score being 25 .

A women faculty score was also calculated for each faculty member responding to the survey. This score consisted of adding the faculty member's responses to three components of the work life survey: adequate gender ratio score; women climate score; and women leadership score. The adequate gender ratio score was a composite of the weighted responses from whether there were too few women in the department, whether or not the department had identified ways to recruit women faculty, and whether or not the department has actively recruited women faculty. The active recruitment response was multiplied by three and the identifying response was multiplied by two. The adequate gender ratio score could range between 6 and 24 for a responding faculty member. A higher gender ratio score indicated more women faculty and/or efforts being made to recruit more women faculty. The women climate score was a composite of responses to whether or not the climate for women in the department is good (this was multiplied by three); whether or not the department has taken steps to enhance the climate for women (this was multiplied by two); and whether or not the department has identified ways to enhance the climate. A faculty member's response to the women climate score could range between 6 and 24 with a higher score indicating a better climate. The women leadership score was a composite of responses to the following: department has made an effort to promote women (this was multiplied by three); department has identified ways to move more women into leadership positions (this was multiplied by two); and the department has too few women in leadership positions. A faculty member's response to the women leadership score could also range between 6 and 24 . It is noted that responses to statements such as " the department has too few women in leadership positions" were recoded so that a higher number response indicates that the faculty member felt there were several women in leadership positions and/or a lot of effort was being made to get women into leadership positions. Since the women's faculty score is the sum of the responses from the adequate gender ratio score, the women climate score and the women leadership score, the women's faculty score ranges between 18 and 72. A score of 45 would indicate a neutral woman's faculty score so that overall, the situation for women as that person perceives it would be neither positive nor negative.

\section{Preliminary Research Analysis}

Some preliminary analysis was done to help determine where gender differences existed before the main purpose of the research was considered. The preliminary analysis also explored whether any differences existed among the factors being considered between STEM and Non-STEM faculty. 
A two-sample t-test was conducted to test for gender differences in the composite work environment score (WE). Men and women faculty were found to have significantly different work environment scores $(p$-value $=.000)$. The sample mean work environment score for men was found to be 62.9 while for women it was 56.2. Recall that a score of 50 indicated a neutral work environment, so on average both men and women faculty reported positive work environments with men reporting on average a more positive work environment than women. A regression analysis was conducted to determine whether the work environment scores differed between STEM and NonSTEM faculty while controlling for gender. The gender indicator variable was set equal to 1 if the faculty member was a man and 2 if the faculty member was a woman. The STEM indicator was equal to 1 if the faculty member was in a STEM discipline and 0 otherwise. It was found that the STEM indicator variable was not significant ( $p$-value $=.804)$ with the gender indicator variable in the model. This study did not find a significant difference in work environment scores between those faculty in STEM and Non-STEM disciplines. The average work environment scores for women in STEM and Non-STEM based on the sample were 56.81 and 56.4, respectively. These were based on sample sizes of 32 and 38, respectively. The average work environment scores for men in STEM and Non-STEM based on the sample were 62.46 and 63.79 , respectively. These were based on sample sizes of 46 and 34, respectively.

A two sample t-test was conducted to determine if male and female faculty members had significantly different self-reported health scores. The self-reported composite health scores between men and women were found to be significantly different $(p$-value $=.000)$. The average male and female health scores for the sample were 29.86 and 26.02, respectively. (Recall that a health score of 30 indicated "good" health, while a health score of 20 indicated "fair" health.) A regression analysis was conducted to see if STEM and Non-STEM faculty members had different health scores while controlling for gender. No significant difference was found between the self-reported health scores of STEM and Non-STEM faculty members while controlling for gender $(p$-value $=.170)$. The health scores for STEM and Non-STEM women faculty in the sample were found to be 25.34 and 26.681, respectively, based on sample sizes of 35 and 47. The health scores for STEM and Non-STEM men faculty in the sample were found to be 29.386 and 30.537 , respectively, based on sample sizes of 57 and 41.

Gender differences were tested for in the various components of three segments making up the women faculty score. The first component considered was the adequate gender ratio score (AG). A regression analysis was conducted with the adequate gender ratio score as the dependent variable. Gender was significant ( $p$-value $=.001)$ with men having significantly higher scores than women. Not surprisingly, it was found that men and women do have significantly different views on whether the present number of women faculty was adequate, on effort being made to identify ways to recruit women faculty, and on the effort being made to recruit women faculty. Responses were considered between faculty in the STEM disciplines and faculty in the Non-STEM disciplines. A regression analysis was conducted on the adequate gender ratio score to determine whether or not there was a significant difference between STEM and Non-STEM faculty responses while controlling for gender. STEM was significant with gender in the model $(p$-value $=.006)$ with faculty in the Non-STEM disciplines having higher adequate gender ratio scores. The average adequate gender ratio scores for STEM and Non-STEM women were 14.944 and 16.50, respectively, based on sample sizes of 36 and 49. The average adequate gender ratio scores for STEM and Non-STEM men were 16.811 , and 19.00 , respectively, based on sample sizes of 61 and 43 . The adequate gender ratio score could range between 6 and 24, with the middle value being 15 .

The second component considered in the women faculty score was the women climate score (WC). A two-sample t-test was conducted between male and female responses to the women climate score. Gender was found to be significant ( $p$-value $=.004$ ). Men perceive the climate for women to be significantly better than women perceive the climate for women. A regression analysis was conducted with women climate score being the dependent variable testing whether or not there was a significant difference in responses between STEM and NonSTEM faculty while controlling for gender. The indicator variable for STEM was not significant when further added to the model $(p$-value $=.954)$ indicating that the climate perceptions of women in both STEM and Non-STEM, are not significantly different. The average women climate scores for women in the sample for STEM and Non-STEM were found to be 18.19, and 17.353 , respectively based on sample sizes of 36 and 48 . The average women climate scores for men in the sample for STEM and Non-STEM were found to be 20.03, and 20.619, respectively based on sample sizes of 60 and 42 . The average women climate score could range from 6 to 24, with 15 being the middle value.

The third component considered was the women leadership score (WL). A two-sample t-test was conducted between male and female faculty women leadership scores. It was found that men significantly perceive that the number of women in leadership positions is adequate and more effort is being made to get women in leadership positions than women ( $p$-value $=.000$ ). A regression analysis was conducted with women leadership scores as the dependent variable testing whether there was a significant difference between STEM and Non-STEM responses while controlling for gender. The indicator variable for STEM was not significant with gender in the model $(p$-value $=.695)$ which implies that the responses for women in both the STEM and Non-STEM areas were not significantly different. The sample average responses for women in STEM and Non-STEM were 15.40 and 16.06, respectively, based on sample sizes of 35 and 47. The sample average responses for men in STEM and Non-STEM were 19.661 and 19.86, respectively, based on sample sizes of 59 and 43 . Women in both the STEM and NonSTEM disciplines found the adequacy of the number of women in leadership positions and the opportunity for women in leadership positions to be about the same.

\section{Health Score versus Women Faculty Score}

This study investigated the relationship between health score and the women faculty score. A regression analysis was conducted with health score as the dependent variable and the women faculty score as the independent variable while controlling for gender and whether or not the faculty member was in a STEM discipline. The STEM indicator variable was not significant and was taken out of the model $(p$-value $=.323)$. The women faculty score was significant in predicting the health score with gender differences taken into account ( $p$-value $=.026$ ). The estimated coefficient for this was positive indicating that 
there is a positive correlation between the women faculty score and the health score controlling for gender. If the women faculty score increases, the health score tends to increase. It is noted, however, that the $\mathrm{R}^{2}$ for this model is only .123 indicating that only $12.3 \%$ of the variation in health scores is explained by gender and the women faculty score. The results for the regression analysis may be found in Table $\mathbf{1}$.

\section{Health Score versus Work Environment Score}

This study investigated the relationship between health score and work environment score. A regression analysis was conducted with health score as the dependent variable and work environment score as the independent variable while controlling for gender and whether or not the faculty member was in a STEM discipline. The STEM indicator variable was not significant $(p$-value $=.711)$ and was taken out of the model. Work environment was significant in predicting the health scores with gender differences taken into account ( $p$-value $=.000$ ). The estimated coefficient for the work environment variable was positive indicating that work environment and health scores are positively correlated taking gender into account. Work environment scores and gender account for slightly over $30 \%$ of the variation in health scores. Results are given in Table 2. For every extra increase of one point in the work environment score, it is estimated that the health score will increase by .252 . Work environment scores still accounted for about $30 \%$ of the variation in health scores even without gender in the model. The women faculty score was added to the model with gender and work environment scores in the model. It was found that the women faculty score was not significant with the work environment score and gender in the model $(p$-value $=.284)$. The work environment score was significant while controlling for

Table 1.

Regression analysis: Health score versus women faculty score and gender.

\begin{tabular}{|c|c|c|c|c|}
\hline \multicolumn{5}{|c|}{ The regression equation is } \\
\hline \multicolumn{5}{|c|}{ health score $=29.4+.065 * \mathrm{WF}-3.324 *$ gender } \\
\hline \multicolumn{5}{|c|}{$\mathrm{WF}=$ women faculty score } \\
\hline \multicolumn{5}{|c|}{183 cases used, 17 cases contain missing values } \\
\hline Predictor & Coef & SE Coef & $\mathrm{T}$ & $p$ \\
\hline Constant & 29.422 & 2.361 & 12.46 & .000 \\
\hline WF & .065 & .029 & 2.24 & .026 \\
\hline Gender & -3.324 & .902 & -3.68 & .000 \\
\hline \multicolumn{5}{|c|}{$(1=\mathrm{M} ; 2=\mathrm{F})$} \\
\hline $\mathrm{S}=5.840$ & \multicolumn{2}{|c|}{$\mathrm{R}-\mathrm{Sq}=12.3 \%$} & \multicolumn{2}{|c|}{$\mathrm{R}-\mathrm{Sq}(\mathrm{adj})=11.3 \%$} \\
\hline
\end{tabular}

Table 2.

Regression analysis-health score versus work environment and gender.

\begin{tabular}{|c|c|c|c|c|}
\hline \multicolumn{5}{|c|}{ The regression equation is } \\
\hline \multicolumn{5}{|c|}{ health score $=15.7+.252 * \mathrm{WE}-2.179 *$ gender } \\
\hline \multicolumn{5}{|c|}{$\mathrm{WE}=$ work environment score } \\
\hline \multicolumn{5}{|c|}{152 cases used, 48 cases contain missing values } \\
\hline Predictor & Coef & SE Coef & $\mathrm{T}$ & $p$ \\
\hline Constant & 15.694 & 2.844 & 5.52 & .000 \\
\hline WE & .252 & .036 & 6.92 & .000 \\
\hline Gender & -2.179 & .877 & -2.48 & .014 \\
\hline \multicolumn{5}{|c|}{$(1=\mathrm{M} ; 2=\mathrm{F})$} \\
\hline $\mathrm{S}=5.19$ & \multicolumn{2}{|c|}{$\mathrm{R}-\mathrm{Sq}=31.6 \%$} & \multicolumn{2}{|c|}{$\mathrm{R}-\mathrm{Sq}(\mathrm{adj})=30.7 \%$} \\
\hline
\end{tabular}

the women faculty score and gender $(p$-value $=.000)$. The work environment score is more significant in predicting the health score than the women faculty score and both are not needed in the model.

\section{Health Score versus 3 Components of Women Faculty Score}

Because the women faculty score is made up of three components, this study wanted to examine the relationship of the three components of the women faculty score and the health score. The three components that make up this score include the adequate gender ratio score (AG), the women climate score (WC), and the women leadership score (WL). A backwards stepwise regression analysis at a .10 significance level was conducted with health score as the dependent variable and adequate gender ratio score, women climate score, and women leadership scores as the independent variables, while controlling for gender. STEM was placed in the initial model to determine whether or not STEM made a difference. Since the $p$-value was for the STEM indicator variable was .271 and this variable was taken out of the model. The only variable remaining in the model besides the gender indicator variable was the women climate variable. The adequate gender ratio variable or the women leadership variable was not significant in predicting health scores with the women climate variable in the model.

A regression analysis was conducted with health score as the dependent variable and women climate score as the independent variable while controlling for gender. The $\mathrm{R}^{2}$ value for this model was .1278 indicating that about $12.78 \%$ of the variation in health scores was explained by women climate score and gender. Interaction between gender and women climate score was tested for significance and found not to be significant. There was about the same amount of variation in health scores explained when the women faculty score $(12.3 \%)$ was used as the independent variable instead of the women climate score. This result suggests that it is the climate that has more of a relationship with health than either the adequate gender ratio or the number of women in leadership positions. Results may be found in Table 3.

\section{Health Score versus Work Environment and 3 Components of Women Faculty Score}

Both a stepwise and backwards regression procedure was performed with health score as the dependent variable with women climate (WC), women leadership (WL), adequate gender ratio score (AG), and work environment (WE) as the independent variables, while controlling for gender. STEM was left out since it was not significant. Both the stepwise and backwards regression procedures ended up with the same model and that model contained only work environment with gender. The results for the backwards regression procedure may be found in Table 4. An interaction term between environment and gender was added to the model, tested for significance, and found not to be significant $(p=.896)$. The interaction term was taken out of the model. Recall that in the study by Miner-Rubino et al. (2009) whether or not a large percentage of women at the level above was a positive factor in determining the health for women was dependent upon whether the particular woman under consideration viewed the climate as positive or negative. Climate was the lead important factor in their study. This current study is having similar findings with regard to climate. This current 
Table 3.

Stepwise regression: Health score versus gender, adequate gender ratio score, women climate score, women leadership score.

\begin{tabular}{|c|c|c|c|}
\hline \multicolumn{4}{|c|}{ Backward elimination. Alpha-to-Remove: .1 } \\
\hline \multicolumn{4}{|c|}{$\overline{\mathrm{AG}}=$ adequate gender ratio score; $\mathrm{WC}=$ women climate score; } \\
\hline \multicolumn{4}{|c|}{$\mathrm{WL}=$ women leadership score; Gender $=1$ if male and 0 if female } \\
\hline \multicolumn{4}{|c|}{ Response is health score on 4 predictors, with $\mathrm{N}=183$} \\
\hline Step & 1 & 2 & 3 \\
\hline Constant & 29.28 & 29.42 & 29.81 \\
\hline \multicolumn{4}{|l|}{ Gender } \\
\hline Coefficient & -3.43 & -3.48 & -3.470 \\
\hline T-Value & -3.80 & -3.94 & -3.940 \\
\hline$p$-Value & .00 & .00 & .000 \\
\hline \multicolumn{4}{|l|}{ AG } \\
\hline Coefficient & .049 & .052 & \\
\hline T-Value & .490 & .530 & \\
\hline$p$-Value & 628 & .594 & \\
\hline \multicolumn{4}{|l|}{ WC } \\
\hline Coefficient & 134 & 145 & 174 \\
\hline T-Value & 1.330 & 1.620 & 2.470 \\
\hline$p$-Value & .184 & .107 & .014 \\
\hline \multicolumn{4}{|l|}{ WL } \\
\hline Coefficient & .022 & & \\
\hline T-Value & .220 & & \\
\hline$p$-Value & .823 & & \\
\hline $\mathrm{S}$ & 5.85 & 5.83 & 5.82 \\
\hline $\mathrm{R}-\mathrm{Sq}$ & 12.94 & 12.91 & 12.78 \\
\hline R-Sq(adj) & 10.98 & 11.45 & 11.81 \\
\hline
\end{tabular}

Table 4.

Stepwise regression: Health score versus women climate, gender, work environment score, women leadership score, and number of women score.

\begin{tabular}{|c|c|c|c|c|}
\hline \multicolumn{5}{|c|}{ Backward elimination. Alpha-to-Remove: .1 } \\
\hline \multicolumn{5}{|c|}{$\mathrm{AG}=$ adequate gender ratio score; $\mathrm{WC}=$ women climate score; } \\
\hline \multicolumn{5}{|c|}{$\mathrm{WE}=$ work environment score; $\mathrm{WL}=$ women faculty score; } \\
\hline \multicolumn{5}{|c|}{ Gender $=1$ if male and 0 if female } \\
\hline \multicolumn{5}{|c|}{ Response is health score on 5 predictors, with $\mathrm{N}=148$} \\
\hline Step & 1 & 2 & 3 & 4 \\
\hline Constant & 15.00 & 14.70 & 15.61 & 15.12 \\
\hline \multicolumn{5}{|l|}{ WC } \\
\hline Coefficient & -.124 & -.159 & -.079 & \\
\hline T-Value & -1.120 & -1.60 & -.990 & \\
\hline$P$-Value & .263 & .111 & .322 & \\
\hline \multicolumn{5}{|l|}{ Gender } \\
\hline Coefficient & -2.220 & -2.100 & -2.050 & -1.970 \\
\hline T-Value & -2.440 & -2.350 & -2.290 & -2.200 \\
\hline$P$-Value & .016 & .020 & .024 & .029 \\
\hline \multicolumn{5}{|l|}{ WE } \\
\hline Coefficient & .278 & .276 & .275 & .256 \\
\hline T-Value & 6.650 & 6.630 & 6.580 & 6.880 \\
\hline$P$-Value & .000 & .000 & .000 & .000 \\
\hline \multicolumn{5}{|l|}{ WL } \\
\hline Coefficient & -.071 & & & \\
\hline T-Value & -.720 & & & \\
\hline$P$-Value & .470 & & & \\
\hline \multicolumn{5}{|l|}{$\mathrm{AG}$} \\
\hline Coefficient & .144 & .132 & & \\
\hline T-Value & 1.45 & 1.35 & & \\
\hline$P$-Value & .149 & .180 & & \\
\hline $\mathrm{S}$ & 5.17 & 5.16 & 5.18 & 5.18 \\
\hline $\mathrm{R}-\mathrm{Sq}$ & 33.24 & 32.99 & 32.14 & 31.67 \\
\hline R-Sq(adj) & 30.89 & 31.12 & 30.72 & 30.73 \\
\hline
\end{tabular}

study did not consider the number of women at the level above, but examined how the responder felt about the adequacy of the number of women and/or efforts to increase the number of women as well the number of women in leadership positions and the efforts made to increase the number of women in leadership positions. The reason for this is that in several departments, there were not any women at the level above. The adequate gender ratio score and the women leadership score were not significant either by just themselves in the model or when put in the model with women climate while controlling for gender ( $p$-values $=.125$ and .077 , respectively). In the MinerRubino et al. (2009) study, it was the perceived climate over the percentage of women at the level above that mattered first when considering overall health of women. This study is also finding that climate has the greater impact.

The present study considered both a women's climate score and an environmental score. The women's climate score asked for responses about the climate for women and possible efforts being made to improve the climate for women within a department. The environmental score asked for responses from the individual about how they thought the environment was for them, whether or not they "fit in", how they were treated by students and staff, and in general about the overall University environment, not just the environment for the Department.

\section{Conclusion}

This research found a relationship between self-reported health scores and women's climate scores while controlling for gender. A relationship was found between self-reported health scores and environment scores while controlling for gender. The second relationship was the more significant of the two accounting for over $30 \%$ of the variation in health scores. Some observations were made as a result of this analysis. It appears that working with individual departments to help improve the climate for women in their departments is useful to improve health scores. However, work needs to be done at addressing the environment for the entire University for everyone if health scores are to improve. The environment considers how the faculty member is treated by students and staff and other colleagues who may be outside the department. The environment score also has the individual considering whether or not they feel isolated in the university, in addition to the department, and whether their research is valued.

This study did not find a relationship between adequate gender ratio and the health scores. When the adequate gender ratio was placed in the regression with gender, it was not significant in predicting health scores $(p$-value $=.125)$. It was also not significant when placed in the model with the women's climate score of the environmental score. The adequate gender ratio scores were higher among Non-STEM faculty than STEM faculty, but self-reported health scores for women in the NonSTEM disciplines were not significantly different than selfreported health scores for women in the STEM disciplines. Work environment scores for faculty in the STEM disciplines were not significantly different from work environment scores in the Non-STEM disciplines. There was a difference based on gender, but women in both STEM and Non-STEM reported about the same average work environment score.

A relationship was found between self-reported health scores and environment scores. It is recommended that if universities want to improve the health of their faculty members, they work 
on improving their overall environment. The adequate gender ratio score did not make an overall difference in women's health scores. Disciplines that reported a higher ratio of women faculty and greater efforts being made to recruit women faculty, did not report significantly higher health scores for women. What did have an effect on health scores was how women thought they were treated, whether they thought their work was valued, and whether they thought their opinions were sought and mattered. This also is what had an effect on health scores for men.

\section{Acknowledgements}

This work was sponsored by an NSF Advance Grant HRD0811239 .

\section{REFERENCES}

Abadie, A., Christy, A., Jones, J., Wang, J. and Lima, M. (2009). Longitudinal survey of female faculty in biological and agricultural engineering. Transactions of the ASABE, 52, 1397-1405.

Abramson, Z. (2007). Masked symptoms: Mid-life women, health, and work. Canadian Journal on Aging, 26, 295-304. http://dx.doi.org/10.3138/cja.26.4.295

August, L., \& Waltman, J. (2004). Culture, climate, and contribution: Career satisfaction among female faculty. Research in Higher Education, 45, 177-192.

http://dx.doi.org/10.1023/B:RIHE.0000015694.14358.ed

Balzer, W., \& Bourdreau, N. (1996). Critical modeling principles when testing for gender equity in faculty salary. Research in Higher Education, 37, 633-658. http://dx.doi.org/10.1007/BF01792950

Barbezat, D., \& Hughes, J. (2005). Salary structure effects and the gender pay gap in academia. Research in Higher Education, 46, 621640. http://dx.doi.org/10.1007/s11162-004-4137-1

Bellas, M. (1993). Faculty salaries: Still a cost of being female? Social Science Quarterly (University of Texas Press), 74, 62-75.

Bourdreau, N., Sullivan, J., Balzer, W., Ryan, A. M., Yonker, R., Thorsteinson, T., \& Hutchinson, P. (1997). Should faculty rank be included as a predictor variable in studies of gender equity in university faculty salaries? Research in Higher Education, 38, 297-312. http://dx.doi.org/10.1023/A:1024946022857

Blackwell, L. V., Snyder, L. A., \& Mavriplis, C. (2009). Diverse faculty in STEM fields: Attitudes, performance, and fair treatment. Journal of Diversity in Higher Education, 2, 195-205. http://dx.doi.org/10.1037/a0016974

Brady, K. L., \& Eisler, R. M. (1999). Sex and gender in the college classroom: A quantitative analysis of faculty-student interactions. Journal of Educational Psychology, 91, 127-145. http://dx.doi.org/10.1037/0022-0663.91.1.127

Bronstein, P., \& Farnsworth, L. (1998). Gender differences in faculty experiences of interpersonal climate and processes for advancement. Research in Higher Education, 39, 557-585. http://dx.doi.org/10.1023/A:1018701722855

Burke, K., Duncan, K., Krall, L., \& Spencer, D. (2005). Gender differences in faculty pay and faculty salary compression. Social Science Journal, 42, 165-181. http://dx.doi.org/10.1016/j.soscij.2005.03.006

Burns-Glover, A., \& Veith, D. (1995). Revisiting gender and teaching evaluations: Sex still makes a difference. Journal of Social Behavior and Personality, 10, 69-80.

Catano, V., Francis, L., Haines, T., Kirpalani, H., Shannon, H., Stringer, B., \& Lozanzki, L. (2010). Occupation stress in Canadian Universities: A national survey. International Journal of Stress Management, 17, 232-258. http://dx.doi.org/10.1037/a0018582

Cress, C. M., \& Hart, J. (2009). Playing soccer on the foot-ball field: The persistence of gender inequities for women faculty. Equity \& Excellence in Education, 42, 473-488. http://dx.doi.org/10.1080/10665680903284523

Dollard, M. F., \& Bakker, A. B. (2010). Psychosocial safety climate as a precursor to conducive work environments, psychological health problems, and employee engagement. Journal of Occupational \& Organizational Psychology, 83, 579-599. http://dx.doi.org/10.1348/096317909X470690

Faculty Worklife Survey (2006). Study of faculty worklife at the University of Wisconsin-Madison.

http://wiseli.engr.wisc.edu/research/w2 facultyversion06.pdf

Fields, C. (2005). Summers to improve college climate. Change, 3, 7.

Glen, D. (2007). Alienation harms female professors, study finds. Chronicle of Higher Education, 53.

Greene, J., Stockard, J., Lewis, P., \& Richmond, G. (2010). Isthe academic climate chilly? The views of women academic chemists. Journal of Chemical Education, 87, 381-385.

http://dx.doi.org/10.1021/ed800042z

Hagedorn, L. S. (2000). Conceptualizing faculty job satisfaction components, theories, andoutcomes. New Directions for Institutional Research, 27, 5-20. http://dx.doi.org/10.1002/ir.10501

Haney, P., \& Forkenbrock, D. (2006). Making fair and predictable salary adjustments for faculty of public research universities. $R e$ search in Higher Education, 47, 111-127. http://dx.doi.org/10.1007/s11162-005-8154-5

Henry, W. J., \& Nixon, H. L. (1994). Changing a campus climate for minorities and women. Equity \& Diversity in Education, 27, 48-54. http://dx.doi.org/10.1080/1066568940270308

Holmgren, K., Hensing, G., \& Dellve, L. (2010). The association between poor organizational climate and high work commitments, and sickness absence in a general population of men and women. Journal of Occupational \& Environmental Medicine, 52, 1179-1185. http://dx.doi.org/10.1097/JOM.0b013e3181fc5c1a

Hult, C. (2005). How's the climate on your campus? Academic Leader, 21, 5-6.

Jacobs, P., Tytherleigh, M., Webb, C., \& Copper, C. (2007). Predictors of work performance among higher education employees: An examination using the ASSET model of stress. International Journal of Stress Management, 14, 199-210.

http://dx.doi.org/10.1037/1072-5245.14.2.199

Laube, H., Massoni, K., Sprague, J., \& Ferber, A. L. (2007). The impact of gender on the evaluation of teaching: What we know and what we can do. NWSA Journal, 19, 87-104.

Messing, K., Lippel, K., Demers, D. L., \& Mergler, D. (2000). Equality and difference in the workplace: Physical job demands, occupational illnesses, and sex differences. Feminist Formations, 12, 21-49.

Miller, J., \& Chamberlin, M. (2000). Women are teachers, men are professors: A study of student perceptions. Teaching Sociology, 28, 283-298. http://dx.doi.org/10.2307/1318580

Miner-Rubino, K., Settles, I. H., \& Stewart, A. J. (2009). More than numbers: Individual and contextual factors in how gender diversity affects women's well-being. Psychology of Women Quarterly, 33, 463-474. http://dx.doi.org/10.1111/j.1471-6402.2009.01524.x

NDSU Internal Evaluation Work Life Survey (2010). http://www.ndsu.edu/forward/program_evaluation

Oaxaca, R., \& Ransom, M. (2002). Regression methods for correcting salary inequities between groups of academic employees. New Directions for Institutional Research, 115, 91-103. http://dx.doi.org/10.1002/ir.55

Piercy, F., Giddings, V., Allen, K., Dixon, B., Meszaros, P., \& Joest, K. (2005). Improving campus climate to support faculty diversity and retention: A pilot program for new faculty. Innovative Higher Education, 30, 53-66. http://dx.doi.org/10.1007/s10755-005-3297-z

Porter, S., Toutkoushian, R., \& Moore III, J. (2008). Pay inequities for recently hired faculty, 1988-2004. The Review of Higher Education, 31, 465-487. http://dx.doi.org/10.1353/rhe.0.0014

Recommended actions for enhancing department climate.

Settles, I. H., Cortina, L. M., Malley, J., \& Stewart, A. J. (2006). The climate for women in academic science: The good, the bad, and the changeable. Psychology of Women Quarterly, 30, 47-58. http://dx.doi.org/10.1111/j.1471-6402.2006.00261.x

Settles, I. H., Cortina, L. M., Stewart, A. J., \& Malley, J. (2007). Voice matters: Buffering the impact of a negative climate for women in science. Psychology of Women Quarterly, 31, 270-281. http://dx.doi.org/10.1111/j.1471-6402.2007.00370.x 
Sprinkle, J. E. (2008). Student perceptions of effectiveness: An examination of the influence of student biases. College Student Journal, 42, 276-293.

Sosin, K., Rives, J., \& West, J. (1998). Unions and gender pay equity in academe: A study of US institutions, Feminist Economics, 4, 25-45. http://dx.doi.org/10.1080/135457098338419

Thacker, R. (1995). Gender, influence tactics, and job characteristics preferences: New insights into salary. Sex Roles, 32, 617-638. http://dx.doi.org/10.1007/BF01544215

Toumanoff, P. (2005). The effects of gender on salary-at-hire in the academic labor market. Economics of Education Review, 24, 179-188. http://dx.doi.org/10.1016/j.econedurev.2004.03.008

Travis, C. B., Gross, L. J., \& Johnson, B. A. (2009). Tracking the gender pay gap a case study. Psychology of Women Quarterly, 33, 410418. http://dx.doi.org/10.1111/j.1471-6402.2009.01518.x

Tytherleigh, M. Y., Webb, C., Cooper, C. L., \& Ricketts, C. (2005). Occupational stress in UK higher education institutions: A comparative study of all staff categories. Higher Education Research \& Development, 24, 41-61.

http://dx.doi.org/10.1080/0729436052000318569

Tytherleigh, M. Y., Jacobs, P. A., Webb, C., Ricketts, C., \& Cooper, C. (2007). Gender, health and stress in English university staff-exposure or vulnerability? Applied Psychology: An International Review, 56, 267-287. http://dx.doi.org/10.1111/j.1464-0597.2006.00254.x
Valian, V. (2004). Beyond gender schemas: Improving the advancement of women in academia. NWSA, 16, 207-220. http://dx.doi.org/10.2979/NWS.2004.16.1.207

Viefers, S. F., Christie, M. F., \& Ferdos, F. (2006). Gender equity in higher education: Why and how? A case study of gender issues in a science faculty. European Journal of Engineering Education, 31, 15 22. http://dx.doi.org/10.1080/03043790500429948

Weistroffer, H. R., Spinelli, M. A., Canavos, G. C., \& Fuhs, F. P. (2010). A merit pay allocation model for college faculty based on performance quality and quantity. Economics of Education Review, 20, 41-49. http://dx.doi.org/10.1016/S0272-7757(99)00037-0

Winefield, A. H., Gillespic, N., Stough, D., Dua, J., Hapuararchchi, J., \& Boyd, C. (2003). Occupational stress in Australian university staff: Results from a national survey. International Journal of Stress Management, 14, 199-210.

Worthington, A. (2002). The impact of student perceptions and characteristics on teaching evaluations: A case study in finance education. Assessment \& Evaluation in Higher Education, 27, 49-64. http://dx.doi.org/10.1080/02602930120105054

$\mathrm{Xu}$, Y. J. (2008). Gender disparity in STEM Disciplines: A study of faculty attrition and turnover intentions. Research in Higher Education, 49, 607-624. http://dx.doi.org/10.1007/s11162-008-9097-4

(2011). Enhancing department climate: A guide for department chairs. 